\title{
Turistas en el edén: La evolución literaria del paraíso
}

\author{
José Manuel Marrero Henríquez \\ Universidad de Las Palmas de Gran Canaria
}

\section{RESUMEN}

Tras las primeras exploraciones realizadas más allá de las Columnas de Hércules, las Islas Canarias pasan a identificarse con los mitos clásicos y en ellas la literatura (Cairasco de Figueroa, A. de Viana), la historiografía (L. Torriani, Abreu Galindo, Viera y Clavijo), la ciencia natural (Humboldt) y los viajeros (O. M. Stone) ubican las ensoñaciones paradisiacas de las Islas de los Bienaventurados, de las Hespérides, de las Afortunadas, de los Campos Elíseos. Esta identificación será el abrevadero publicitario en el que se fundamentará la explotación turística que, desde finales del siglo XIX, alterará no sólo el paisaje de las islas, sino también su representación literaria. En la obra de Fco. González Díaz, A. Quesada, C. Laforet, E. de Andrade, E. Jünger, D. Lodge, L. Alemany, M. Houllebecq, L. Silva o J. M. Marrero Henríquez reaparecerá la imaginería del paraíso, ya para cuestionar con ironía su autosuficiencia como signo literario, ya para criticar su uso mercantil, ya como imagen de desolación, ya como exigencia de futuro.

Palabras clave: Paisaje literario, paraíso, turismo, Islas Canarias, publicidad, representación, ecocrítica.

\section{Tourists at eden: Literary evolution of paradise}

\begin{abstract}
After the first explorations beyond the Herculean Columns took place, the Canary Islands turned to be identified with classical myths, and literature (Cairasco de Figueroa, A. de Viana), historiography (L. Torriani, Abreu Galindo, Viera y Clavijo), natural science (Humboldt), and travellers (O. M. Stone) located there the paradisiac fantasies of the Islands of the Blessed, the Hesperids, the Fortunate Islands, and the Elysean Fields. Such identification will serve as publicity for the tourist exploitation that, since the end of the 19th century, will modify not only the islands landscape, but also its literary representation. In the works of Fco. González Díaz, A. Quesada, C. Laforet, E. de Andrade, E. Jünger, D. Lodge, L. Alemany, M. Houllebecq, L. Silva, or J. M. Marrero Henríquez classical imagery of paradise will reappear, either to ironically question its self-sufficiency as literary sign, to criticize its commercial use, as an image of desolation, or as an exigency for the future.
\end{abstract}

Keywords: Literary landscape, paradise, tourism, Canary Islands, publicity, representation, ecocriticism. 
El tránsito demorado por los caracteres mítico-paradisíacos con que las Islas Canarias han sido identificadas ineludiblemente conducirá a la confrontación de tales caracteres con la realidad paisajística del archipiélago, al menos si de ese tránsito se esperan hallazgos que pongan de relieve cómo la intervención en el territorio —urbanística, demográfica, turística o de cualquier otra índole - afecta a la evolución de su representación literaria, y cómo de tal evolución cabrá extraer lecciones éticas y estéticas que sirvan para reflexionar sobre el paisaje, sobre el paisaje literario denominado paraíso, sobre la íntima relación que entre ambos existe y sobre el papel que los factores externos a la institución literaria juegan en la teoría y en la crítica, en el análisis y en la interpretación literarios.

Sin duda la literatura, la teoría y la crítica se alimentan de la literatura, pero cuando ésa es la exclusiva fuente de su nutrición, la literatura y los estudios literarios corren el riesgo de cerrarse sobre sí mismos en una suerte de universo disciplinar autónomo y ajeno a la realidad histórica en que se insertan. La afirmación de Jacques Derrida de que «il n'y a pas de hors texte» (202), de que nada hay fuera de texto, representa muy bien una manera de entender la escritura literaria en que sólo los paisajes que pueblan la historia de la literatura están destinados a ser los únicos signos pertinentes con que la creación artística cuenta en su haber para la producción de otros nuevos, los únicos signos pertinentes en la compleja gramática de las convenciones literarias. A tal manera de entender la textualidad literaria han contribuido el estructuralismo, el formalismo ruso, la nueva crítica estadounidense y el postestructuralismo que, para superar el exceso de biografismo, relegaron al autor, favorecieron al texto e hicieron hincapié en que la literatura está hecha de palabras y en que el lenguaje de la literatura llama la atención sobre sí mismo, por traer a colación el conocido aserto de Roman Jakobson sobre la función poética del lenguaje. Por el camino hacia el texto no sólo quedó el autor, también quedó la realidad, pues la literatura, antes que llamar la atención sobre ella, crea la suya propia.

Así las cosas, la evolución literaria del paraíso se debería más al impulso de hacer y rehacer un motivo de especial vitalidad literaria, que al efecto que la observación directa de un paisaje específico pueda tener en su formalización literaria. Pero sucede que, entrado el siglo XXI, en plena era del antropoceno, cuando ha quedado científicamente consensuado que el desarrollo de la especie humana viene repercutiendo de manera negativa en la salud de la tierra considerada en su conjunto como un inmenso ecosistema, cuando la dimensión global de la disminución de la biodiversidad, del cambio climático y de la sobreexplotación de los recursos naturales es un hecho cuya complejidad afecta a todos los órdenes de la actividad humana, la teoría y la crítica literarias han encontrado novedosos motivos para abandonar los discursos ensimismados en la condición sígnica de la realidad y volver sus ojos a evi- 
dencias olvidadas: que la literatura dice del mundo y que al decir del mundo decide sus formalizaciones ${ }^{1}$.

Los paisajes que pueblan la naturaleza reclaman ahora su derecho a desempeñar en cuanto seres reales y tangibles, y no sólo en cuanto signos literarios o en cuanto motivos artísticos, un papel de mayor relevancia cuando se sopesa el valor simbólico de su presencia en un poema, cuando se menciona el efecto de su uso como leit motiv en un relato, cuando se escoge una perspectiva y una luz para realizar su descripción, o cuando se trata de las consecuencias éticas y estéticas de su incorporación en una obra. El caso del trasvase de influencias entre las transformaciones de la realidad paisajística y la imagen del paraíso que sobre la descripción literaria de las Islas Canarias se ha asentado es de relevante interés al respecto.

Son varios los mitos de la antigüedad clásica que han contribuido a conformar el sólido vínculo que une a las Islas con el paraíso y que son lugar común en la literatura, en la historiografía, en la geografía, en las guías turísticas y en el aparato propagandístico de las agencias de viaje: los Campos Elíseos, las Islas de los Bienaventurados, las Islas Afortunadas, el Jardín de las Hespérides, el Paraíso y el Jardín de las Delicias, la Atlántida y San Borondón. En estos mitos laten, como señala Marcos Martínez, diversas tradiciones de la Antigüedad: la escatología o el conjunto de doctrinas sobre el destino de la persona al morir; el mito de la Edad de Oro y los temas relacionados del paisaje ideal o locus amoenus y la Arcadia; la utopía; la paradoxografía o conjunto de escritos de asuntos increíbles, cosas maravillosas y extraordinarias e insólitas; la literatura de viajes (22). De entre las múltiples fuentes clásicas que Marcos Martínez explora valga mencionar, de manera resumida, Hesiodo para la Edad de Oro; Virgilio para la Arcadia y el locus amoenus; la descripción del país de los feacios en la Odisea, la de la ciudad de los justos en los Trabajos y los días de Hesiodo, el estado ideal en la República y en Las Leyes y La Atlántida en el Timeo y en el Critias de Platón para la utopía; los escritores paradoxográficos como Estratón de Lámpsaco para el relato de cosas incré́bles; el Periplo de Hannón por la costa occidental africana del siglo V a.C. para la literatura de viajes, también la Odisea homérica o El viaje de los argonautas de Apolonio de Rodas (29-31).

En no poca medida la visión paradisíaca omnipresente en las historias de las Islas Canarias se debe a la amalgama de textos heterogéneos en la que lo legendario y lo documental se entrelazan en un relato que ha incorporado sin discriminación la obra de poetas, dramaturgos, filósofos, historiadores, geógrafos, enciclopedistas y escritores de maravillas, padres de la iglesia y autores cristianos, autores árabes, libros de viajes y de navegaciones, humanistas, lexicógrafos, comentaristas, glosógrafos o libros bíblicos. Con «el extenso

\footnotetext{
${ }^{1}$ Véase Marrero Henríquez «La interpretación literaria», «Poetics of Beauty» y «La crítica como refugio».
} 
catálogo de las fuentes utilizadas por [...] cronistas e historiadores a partir del siglo XVI» Marcos Martínez ha elaborado una narración de los tópicos paradisíacos asociados a las Islas Canarias que por su carácter sintético vale la pena reproducir:

[En] los confines y lugares extremos de la tierra, más allá de las columnas de Heracles, atravesando el tenebroso Océano, existen unas islas paradisíacas, que gozan de un clima eternamente primaveral y cuyos campos producen toda clase de alimentos y frutos sin necesidad de trabajo alguno. En ellas [...hay] un maravilloso Jardín, en el que está el árbol que contiene la esencia de la inmortalidad y produce manzanas de oro [...]. Las almas de los Bienaventurados llevan allí una existencia edénica, libres de preocupaciones, por lo que no hay ninguna duda de que en estos parajes está el ansiado Paraíso. (21).

En el camino que va del mito a la realidad hay textos que se remontan a los siglos I y II d.C que «aluden [al...] Archipiélago como realidad geográfica, como unas islas verdaderas existentes en el océano Atlántico [en los que se] habla también de Islas Afortunadas, se dan sus nombres y ciertas características topográficas, [y en los que...] se siguen introduciendo [...] elementos de la literatura maravillosa y utópica» $(50)^{2}$. Estos textos, que se suceden en el tiempo, llevan a las Islas Canarias situadas en el borde del mundo conocido a pasar de manera inexorable «del mito a la [...] realidad cuando en los siglos XIII y XIV, merced a los viajes de genoveses, portugueses, catalanes, mallorquines, aragoneses, franceses, castellanos, vizcaínos, andaluces, ingleses y napolitanos, se identifican cartográficamente las Islas Canarias» y a ellas en crónicas y libros de viajes se asocian las características paradisíacas de las islas míticas griegas y latinas. Como hecho significativo de este anclaje del

\footnotetext{
${ }^{2}$ Presta especial atención Marcos Martínez a un pasaje de las Etimologías en que San Isidoro, en el s. VII, identifica las Islas Canarias con las Islas Afortunadas, que son la traducción latina de las makáron nêsoi griegas y que, aunque míticas, no duda en describir en la costa occidental africana: «las Islas Afortunadas nos están indicando, con su nombre, que producen toda clase de bienes; es como si se las considerara felices y dichosas por la abundancia de sus frutos. De manera espontánea producen frutos los más preciados árboles. Las cimas de las colinas se cubren con vides sin necesidad de plantarlas; en lugar de hierbas nacen por doquier mieses y legumbres. De ahí el error de los gentiles y de los poetas paganos, según los cuales, por la fecundidad del suelo, aquellas islas eran el paraíso. Están situadas en el Océano, en frente y a la izquierda de Mauritania, cercanas al occidente de la misma y separadas ambas por el mar» (XIV, 6,8). De los textos anteriores a las Etimologías que también ubican en las Canarias los mitos clásicos, destaca Marcos Martínez Historia Natural (VI 37, 202-205) de Plinio el Viejo (s. I d.C.), a la que siguen en el tiempo Guía Geográfica (IV 6, 14) de Ptolomeo (s. II d.C.), Collectanea rerum memorabilium (56, 7) de Julio Solino (s. III d.C.), Bodas de Mercurio y la Filología (VI 702) de Marciano Capela (s. V d.C.) y, posiblemente, Cosmografía (V 33-34) del llamado «Geógrafo de Rávena» (ca. 800 d.C.). Posteriormente Marcos Martínez considera que la primera mención de las Islas Canarias en la Antigüedad como entidades geográficas realmente existentes, se encuentra en Adversus nationes de Arnobio (ca. 300), de quien se tiene noticia a través de De viris illustribus de San Jerónimo (50-51, 59-60).
} 
mito en la realidad Marcos Martínez refiere el año 1339, «cuando por primera vez se dibujan con sus contornos casi reales dos de [las...] islas en el planisferio de Dulcert» $(51)^{3}$.

A partir de entonces el prestigio de los mitos clásicos se traspasa no sólo a obras fundacionales de la Literatura Canaria, como las de Cairasco de Figueroa (1538-1610) y Antonio de Viana (1578-?), sino también a la obra del reputado ingeniero Leonardo Torriani (1500-1585), a la de los historiadores Abreu Galindo (ca. 1535) ${ }^{4}$ y Viera y Clavijo (1731-1813), a la del fundador de la geografía moderna, Humboldt (1769-1859) y a la de viajeros decimonónicos que describen minuciosamente, día a día, su discurrir por tierras canarias, como Olivia M. Stone. Y será precisamente a partir de finales del siglo XIX cuando el signo paradisíaco inicia un periodo de difusión que alcanza al presente y que, en la medida en que la tecnología lo ha permitido, lo ha llevado más allá de la cultura literaria y de las guías y folletos turísticos. A la incipiente propaganda destinada al primer turismo de salud y reposo siguió la planificación comercial del signo paradisíaco proyectada por Francisco González Díaz y posteriormente abordada por las juntas provinciales de turismo creadas en los años treinta del siglo XX, la explotación sistemática del territorio y de la imagen del territorio iniciada tras el primer vuelo chárter de 1957 y la entrada en juego de los tour operadores y, finalmente, su utilización comercial como reclamo en diversos medios de comunicación audiovisuales —radio, televisión, cine, páginas web- y en diferentes formatos —anuncios, series, documentales, cortos, largos, páginas institucionales y privadas - cuyo objetivo último es crear una atractiva imagen de marca para vender mejor el producto 5 .

De manera paradójica, la inflación del uso propagandístico de la imagen paradisíaca ha venido acompañada del deterioro del lugar que la sustenta, y la consecuencia, también paradójica, ha sido que, a medida que el paraíso se ha ido fijando como «marca de la casa», ha iniciado un progresivo proceso de relevantes transformaciones literarias, de manera incipiente a partir de finales del siglo XIX, y significativamente a partir de los años 60 del siglo XX. Como se verá en los ejemplos que siguen, este proceso pasa por la loa de resonancias clásicas de las Canarias y de sus habitantes que se extiende desde el siglo XVII hasta el XIX sin modificaciones significativas, y de la que son paradigma los autores antes citados - Cairasco, Viana, Torriani, Abreu

\footnotetext{
${ }^{3}$ Para una extensa bibliografía sobre las expediciones medievales a Canarias véase Marcos Martínez (156-157).

${ }^{4}$ Véase los comentarios al respecto que en el prólogo de la Historia de Abreu Galindo hace Alejandro Cioranescu (vi).

${ }^{5}$ Sobre las representaciones del espacio turístico canario en literatura, cine, museos, salas de arte y otros medios, véase M. de Santa Ana. En lo referente al cine véase también L. Roca.
} 
Galindo, Viera y Clavijo, Humboldt y O. Stone-; por el proyecto positivista que Francisco González Díaz expuso en su excelente ensayo Cultura y turismo (1910) y mediante el cual proponía hacer una planificación urbanística y una intervención en el territorio respetuosas con las características naturales y climatológicas de unas Islas émulas de las Hespérides para atraer turistas y con ellos conseguir el desarrollo cultural, económico y social de los canarios; por el tratamiento irónico que del mito hace Alonso Quesada en Banana Warehouse (1916-1917), habitante de una ciudad comercial dominada por empresas y turistas británicos que se abre a la modernidad, pero en la que los proyectos de González Díaz de conseguir una suerte de «Grecia atlántica» no parecen haber llegado a término; por el lugar legendario cuya hermosura, extrema y adversa en ocasiones, en ocasiones apacible y pintoresca, fértil, vital y paradisíaca a veces, sólo la protagonista es capaz de percibir con plenitud, pues, como sugiere el título de la novela de Carmen Laforet La isla y los demonios (1952), los demás personajes están ocupados en rencillas, ambiciones, recelos, pasiones, resentimientos y frustraciones que los inhabilitan para la observación de la naturaleza; por la visión irónica del paraíso que raya el sarcasmo cuando Luis Alemany, en Los puercos de Circe (1973), contrapone a la del oriundo la visión idílica del edén y de sus habitantes que el visitante tiene; por el paraíso que, en Lanzarote, de M. Houllebecq, se compra en una agencia de viajes y que, ya en destino, desempeñará el papel de escenario más bien intrascendente donde disfrutan del sexo turistas desinhibidos; por la supervivencia del mito en parajes protegidos y en la imagen de cliché de quienes visitan las Islas, como sucede en La niebla y la doncella (2002), de Lorenzo Silva; y, en fin, por la crítica explícita de la destrucción de un lugar prestigiado de paradisíaco en la literatura, la historia y la geografía en textos de J. M. Marrero Henríquez, E. de Andrade, E. Jünger y D. Lodge.

Cairasco de Figueroa en Godofredo famoso (1602) incorpora unas octavas reales al original italiano de la Jerusalén Libertada de Torcuato Tasso en las que aprovecha «el marítimo paseo» para contar «[...] las futuras y pasadas / Fortunas de las Islas Afortunadas» y contextualizar al pueblo aborigen en un espacio privilegiado cuya naturaleza está plagada de resonancias clásicas:

Del cielo puso a parte lo más puro; del aire entresacó lo más templado; de la tierra y del mar, lo más siguro; de la fertilidad, lo más granado; del tiempo, lo más blando y menos duro; de las estrellas, lo mejor parado; de las fuentes y arroyos, los mejores; lo propio de las selvas, frutas, flores.

[...]

Aquí los frescos aires, las mareas, el toldo de las nubes relevadas, 
de los floridos campos las libreas, los verdes bosques, aguas plateadas, el temple, sanidad, ricas preseas, los cantos de las aves variadas en sagrado silencio, en paz entera conservan una eterna primavera.

Aquí florece la admirable selva que el nombre ha de heredar del gran Doramas, de no entrará discreto, que no vuelva con rico asombro de su sombra y ramas. El que mejor escribe se resuelva, que es digna de sus versos y epigramas, y aun al sagrado Apolo le parece que no han de darle el punto que merece.

Perdone el Helicón, Pindo y Parnaso, los celebrados bosques de Acidalia, las fuentes donde Febo llena el vaso y las frondosas selvas de Rosalía; perdone el oriente y el ocaso y, cuando salga, el Tívoli en Italia, Cintra en España, el Aranjuez y el Pardo, que, opuesto al parangón, su verde es pardo.

\section{$[\ldots]$}

Los antiguos filósofos, que fueron los que lo más oculto investigaron, como estas calidades y otras vieron, en tanto aquestas islas estimaron, que por Elíseos Campos las tuvieron y Bienafortunadas las llamaron, diciendo que no hay parte acá en el suelo que así se afronte y frise con el cielo. $(97,98,100)^{6}$

Antonio de Viana, en Antigüedades de las Islas Afortunadas (1604), el poema épico por excelencia de la conquista de Canarias, sitúa también a los pueblos prehispánicos en el marco mítico de una naturaleza portentosa. Primero Viana localiza con precisión geográfica las Islas:

En el océano mar, término Adlántico, yacen en medio de las ondas varias, a quien resisten firmes y altas rocas de pardas peñas y arenosas playas, las islas: son Canaria, Tenerife, Palma, Gomera, Hierro, Lanzarote, Fuerteventura, tan cercanas de África,

\footnotetext{
${ }^{6}$ Citado por Marrero Henríquez El paisaje literario. Antología.
} 
que ochenta leguas distan de su costa,
y de Cádiz doscientas y cincuenta.
Nordeste, en ellas, Sudueste, Oeste,
y Leste, vientos favorables, soplan.
Llamaron otro tiempo a Tenerife
Nivaria, y a La Palma, Pintuaria;
Casperia, a la que agora es la Gomera;
Capraria, o Hero, al Hierro, y Lanzarote,
Yunonis y Pluytula o Mahorata,
Fuerteventura, nombres antiquísimos.
Aquel que fue rompiendo el mar salado
sulcando el golfo del cerúleo seno
y descubrió los cabos y estrechuras
de Mauritania, cuando de las Indias
vio la grandeza de riquezas próspera,
halló para el deseo el non plus ultra
en estas siete venturosas islas. (108-109)

Y después de describir pormenorizadamente las bondades extremas de su suelo lo prestigia por sus características clásicas y concluye:

\author{
Llamáronlas los Campos Elíseos, \\ diciendo que el terreno Paraíso, \\ del ímpetu del golfo y mar cubierto, \\ entre ellas tiene su glorioso sitio. $(110)^{7}$
}

Abreu Galindo, en Historia de la conquista de las siete islas de Canaria $(1602)^{8}$, trae a colación el vínculo de las Canarias con las islas «Dichosas y Fortunadas» (19). Por su afán de historiador veraz, Abreu Galindo considera en primera instancia que no pudo llamárseles a estas islas Dichosas por «la [...] copia de frutos que había en estas islas. La cual razón, aunque en nuestros tiempos sea verdadera, mas no lo es, considerado el tiempo en el cual se le[s] impuso el nombre de Dichosas, que fue antes de la redención del mundo, en tiempo de las divisiones entre César y Pompeyo» (20). Pero admite finalmente que la templanza de su clima y las posibilidades de su suelo permiten dar por «averiguado competirles el nombre de Dichosas» (23).

El vínculo también es aceptado por el ingeniero italiano Leonardo Torriani, autor de un buen número de fortificaciones a orillas del Tajo y de los trabajos de conducción de aguas y de arquitectura civil de Lisboa, donde falleció en 1628. Su obra Descripción e historia de las Islas Canarias (1592) fue el resultado del encargo de recabar «información para los informes que había de

\footnotetext{
${ }^{7}$ Citado por Marrero Henríquez El paisaje literario. Antología.

${ }^{8}$ En el prólogo de la Historia, Alejandro Cioranescu considera que 1602 es la fecha en que el manuscrito presenta las últimas adiciones y correcciones auténticas (xiii), aunque, como el mismo Cioranescu afirma, «las ediciones impresas incluyen en el título la fecha de 1632» (ix).
} 
remitir a la Corte y [...] al Rey, sobre las necesidades y realización de obras militares» (7). Se trata de una relación oficial y de interés práctico escrita después de dos viajes, el primero a la isla de La Palma con el objetivo de construir un muelle y un torreón, y el segundo con el encargo de visitar todas las fortificaciones de Canarias e «informar sobre la mejor manera de completar el sistema defensivo del archipiélago» (16). A pesar de su bagaje técnico y de su misión práctica, Torriani dedica el primer capítulo de su Descripción e historia de las Islas Canarias a discutir «Si las Islas Canarias son las verdaderas Afortunadas» (45), el segundo capítulo a exponer «Del número de las Canarias y de sus nombres» (49) y el tercer capítulo a explicar «Por qué estas islas fueron llamadas Afortunadas y después Canarias» (52).

Viera y Clavijo, en su monumental Historia General de las Islas Canarias (1772), después de describir la benevolencia de su clima y de las estaciones del año, discute en varios capítulos del libro I «por qué fueron reputadas por Campos Elíseos y se llamaron Islas Afortunadas» (25), «si son las Hespérides y las Górgades» (30), «su epíteto de Atlántidas» (37) o «si fueron las Canarias parte de la Atlántida de Platón» (37).

A caballo entre los siglos XVIII y XIX, Humboldt, en sus Cuadros de la naturaleza, discute sobre la «cuestión relativa a la situación del Atlas de los antiguos [que se agita] muchas veces en los tiempos modernos» (206) y se hace eco de las conclusiones de Julio Luis Ideler (1800-1842), que considera tanto fuentes míticas como científicas, y para quien «el Atlas de Homero y de Hesíodo no puede ser otro que el pico de Tenerife, y es preciso buscar en el África septentrional el de los geógrafos griegos y romanos» (207). A pesar de que su escritura está plagada de estadísticas, datos topográficos y terminología especializada de botánica y mineralogía, Humboldt describe con arrobo la belleza del Valle de la Orotava, en Tenerife, en su Viaje a las regiones equinocciales, y en una carta de 23 de junio de 1799 a su hermano Guillermo, a dos días de zarpar desde Tenerife hacia Venezuela, confiesa: «me voy casi en lágrimas; me hubiera gustado establecerme aquí; y apenas acabo de dejar la tierra de Europa. ¡Si tú pudieras ver esos campos, esos seculares bosques de laureles, esos viñedos, esas rosas! ¡Aquí engordan los cerdos con duraznos!» (202).

Y ya en el XIX, Olivia Stone, al inicio de Tenerife y sus seis satélites, un libro pormenorizado sobre los paisajes, hábitos y costumbres e incidentes de su periplo en el que intenta «representar las Islas Canarias tal como son y como las descubrimos en nuestros viajes» (9), en el capítulo primero afirma que «antiguamente la Islas Canarias eran bien conocidas. En tiempos de Homero y Hesíodo y Píndaro eran las 'Islas Afortunadas'. Estrabón las llama 'Islas de los Felices', y desde tiempos mitológicos Estacio Seboso y Plinio las han denominado 'Jardín de las Hespérides'. Se mire como se mire, se merecen en la actualidad los agradables nombres que les han dado en el pasado, y las Islas Felices de los griegos y los romanos son, verdaderamente, las Islas Felices del presente»(19). A Olivia Stone, dadas estas características, le re- 
sulta extraño que sean tan poco conocidas, y tras preguntarse «cómo han caído tan completamente en el olvido [...concluye que] sólo podremos encontrar una respuesta al constatar que son una provincia de España» (19).

Al comenzar el siglo XX, Francisco González Díaz pretende rescatar de ese olvido aludido por Olivia Stone a las Canarias paradisíacas para aprovechar la explotación del incipiente turismo y mejorar las condiciones socioeconómicas de los isleños. Mediante un sistema planificado de propaganda, González Díaz recurre al símil con el paraíso, compara el bienestar de las Hespérides y de las Afortunadas con la bonanza del clima del Archipiélago y propone la difusión de sus benefactoras características mediante su demostración empírica.

Sabe muy bien González Díaz que tanto como la bonanza de un lugar, es la literatura escrita sobre ese lugar la clave para tener éxito a la hora de atraer turistas. Los libros de viajes y la descripción poética de paisajes pintorescos han fomentado el turismo: «los románticos trajeron a la literatura, y de la literatura pasó a la vida, el sentimiento de lo exótico [...] Chateubriand y Lamartine fueron a Oriente, [...] Dumas el mayor midió incansable con las piernas las rutas de Europa y Stendhal usó acaso por vez primera [...] el término turista en el título de un libro suyo» (186). De la literatura ha surgido el diletantismo viajero y «la impetuosa corriente de burgueses ilustrados y ricos que marchan en pos de lo pintoresco» (186). El caso de Inglaterra es muy significativo, pues con su literatura «Inglaterra creó el turismo» (202), un turismo de interior que, atraído por Walter Scott, visita «los románticos lagos escoceses, [... o que tras leer a] los lakistas (Wordsworth, Coleridge, Southey, Quincey)» (202) desea llegar hasta el Lake District. Por Shakespeare, afirma González Díaz, los turistas van a Strafford y, por la tumba de Lord Byron, Newstead Abbey se ha convertido en un lugar de peregrinación. De manera similar, el Quijote atrae sobre La Mancha, «en Altorf inquieren la flecha de Guillermo Tell, en Tarascón husmean la huella imaginaria de Tartarín» y los suizos explotan con habilidad utilitarista «la escenografía histórica» de las figuras de Voltaire, Rousseau, Calvino y Amiel (204). El mito literario es utilizado por González Díaz con mentalidad positivista y descrito a base de datos, estadísticas y estudios científicos. Afirma González Díaz que

\begin{abstract}
importaría sobremanera organizar un sistema de publicidad que llevara hasta los últimos rincones del planeta el conocimiento de la climatología isleña con datos, con relaciones, con detalles, con extractos de estudios comparativos que revelaran íntegro en donde quiera el portento de nuestra primavera inacabable. En las estaciones ferroviarias, en los hoteles, en los periódicos de gran circulación, en los círculos elegantes de las poblaciones de primer orden, en las agencias de viajeros, en las guías, en todo lo que sea un medio útil de propaganda, debemos exhibir al país canario como mansión privilegiada, única, como región paradisíaca, predilecta de la naturaleza. (124).
\end{abstract}

No duda González Díaz de que «el concepto de eternamente primaveral, que hemos estereotipado en el diario elogio de nuestra óptima climatología, 
arranca [a los turistas] de sus países de origen y [los] orienta hacia las viejas Hespérides, en donde se prometen probar [...] la manzana de la salud y la felicidad» (198). Y con convicción darwinista, tampoco duda de que si el Mediterráneo y la situación y características geográficas de las islas griegas propiciaron el contacto mercantil y cultural entre pueblos que dio como resultado la cultura clásica, el destino de las Islas Canarias y el Atlántico es el correspondiente moderno al de la Grecia antigua y el Mediterráneo, pues las Islas Canarias, «colocadas en [el océano Atlántico, que es] el camino de las peregrinaciones modernas [y] el cruce de las rutas oceánicas, punto de estación y de parada entre los continentes [...son] hijas del tiempo en cuanto el tiempo significa cumplimiento de las profecías que se encierran en la ley de universal evolución, en el desarrollo progresivo de la humanidad» (5-6).

Para atraer turismo pretendía González Díaz no sólo aprovechar el clima de Canarias sino también cuidar su imagen literaria clásica, embellecer las cualidades propias de su naturaleza, sus paisajes, sus pueblos y sus ciudades, mejorar sus infraestructuras y crear un sistema universal de escuelas inspirado en la línea pedagógica de Pestalozzi, Fröbel y Sarmiento que resolviera el grave problema de analfabetismo que por entonces azotaba España y, en particular, Canarias 9 . Turismo, cultura y conservación del medio eran conceptos íntimamente ligados en la visión positivista del paraíso de González Díaz. Si levantara la cabeza, volvería a recostarla. Porque si es cierto que, en lo que a la naturaleza concierne, Canarias es un lugar privilegiado por su amable clima y envidiable biodiversidad, también lo es que tanta bondad parece haber resultado insoportable, pues a medida que el archipiélago se ha incorporado a la modernidad y ha hecho de su suelo receptáculo del turismo de masas, se ha dotado, con el tesón de las hormigas, de un buen número de calamidades: elevados y numerosos hoteles interceptan los flujos de arena que dan vida a sus playas, feas casas llamadas «garajeras» irrumpen en el rincón más insospechado del campo, el cauce de los barrancos se obstaculiza y se impide el libre fluir de sus ocasionales escorrentías, las actividades agrícolas y pesqueras se reducen y se cementa el perímetro de las islas con caótica perfección ${ }^{10}$.

\footnotetext{
${ }^{9}$ Sobre los ideales pedagógicos de González Díaz, véase Marrero Henríquez «Francisco González Díaz: regeneración cultural, repoblación forestal y ecología» y «Cultura y turismo o el imperativo geográfico del paisaje insular».

${ }^{10} \mathrm{Al}$ respecto, algunos datos son tan reveladores como ciertas cifras espeluznantes. En las tres décadas que van de 1940 a 1970 la población de Gran Canaria se multiplica por dos veces y media [...y] la llegada de turistas [...] se multiplica por quince» (Millares 379). En las dos décadas siguientes el crecimiento sigue el mismo ritmo arrollador y la entrada de turistas se multiplica casi diez veces: si en 1968 entraban a Gran Canaria 335.296 turistas en el año 2000 lo hicieron 3.109.066. Ese mismo año la cifra de entrada de turistas en todo Canarias roza la desorbitada cifra de los diez millones (ICE). Y los datos y previsiones más recientes de diversos organismos e instituciones no auguran un futuro mejor. El diagnóstico aportado el 24 de septiembre de 2001 por el equipo técnico de la Consejería de Turismo,
} 
$\mathrm{Si}$, como afirma Jean Baudrillard, la hiperrealidad liquida al referente, puede afirmarse que, de manera similar, el paraíso liquida al paisaje. Por más que la presión de la industria turística haya propiciado una intervención urbanística en las costas de Gran Canaria, Fuerteventura, Lanzarote y Tenerife poco afortunada y, en ocasiones, de más que dudosa legalidad, la imagen del paraíso se ha hecho fuerte en cuanto hiperrealidad — realidad sin referente real, signo autosuficiente que suplanta la realidad - y ha encontrado, como antes el lenguaje literario, en sí misma su propia razón de ser. En la época del turismo de masas el paraíso intenta obstinadamente suplantar al paisaje y sobrevivirlo, o vivir sobre él. Lo conseguirá en la propaganda de los diversos medios de comunicación, pero no en la literatura que se nutre del mundo para proponer nuevas formalizaciones de la realidad, pues a partir de los primeros años del siglo XX y, sobre todo a partir de los años 60, la literatura se hará eco de las transformaciones paisajísticas modificando el paraíso merced a perspectivas críticas de variada índole.

Alonso Quesada, en su obra Banana Warehouse (1916-1917) describe el paraíso y sus habitantes con manifiesta ironía. La novela desarrolla «la acción [...] en [la isla de] Platanópolis, lugar imaginario» (187) y ha sido realizada por un grupo de jóvenes del lugar, tal como afirma Veremundo del Muermo y Esparavanes en el prólogo. Veremundo describe un lugar pleno de reminiscencias clásicas paradisíacas: «escogido lugar de la naturaleza» (196), «lejano y poco accesible» (198), «pintoresco y desviado del orbe» (197), «el país más maravilloso del orbe» (199), «lugar preferido por los dioses» (196). Veremundo admite que «nunca [vio] país como aquel país ni aun en los relatos deslumbradores de Scharezada» (35) y asocia la capital de la isla con las bondades paisajísticas virgilianas al tildarla de «geórgica ciudad» (197). Y Veremundo, «que había visitado Platanópolis para estudiar los caracteres de aquella raza» (196), extiende la apariencia edénica del lugar a todos sus habitantes: «cada ciudadano es un dechado de pureza moral inconcebible [...] los jóvenes ignoran toda maligna cosa y es tal la honradez de sus corazones, que es muy frecuente hallar comerciantes

coordinado por Andrés de Souza para la elaboración de las Directrices del Turismo, califica la presión demográfica que soportan Gran Canaria y Tenerife de «descomunal» y advierte que tales islas son ya de los territorios insulares más poblados del mundo y que es necesario «limitar el crecimiento». En tal diagnóstico resulta paradigmático del desastroso desarrollo de las islas el ejemplo de Fuerteventura, pues sobre su suelo «se localizan 81,6 residentes no canarios por cada 100 ciudadanos nacidos en la isla». Y el otrora excepcional ejemplo de Lanzarote hoy no le queda a la zaga, pues tal diagnóstico considera «'un disparate insostenible' el ritmo de crecimiento registrado en Lanzarote y Fuerteventura en los tres últimos años, con un índice del 35\% en el caso lanzaroteño y un 30\% en el caso majorero» (G.H.M. 15). Si a estas cifras se añaden las previsiones del Ministerio de Fomento sobre la tercera pista del aeropuerto de Gran Canaria, el panorama deviene desolador. En el año 2000 se registraron en el aeropuerto 9.376 .640 pasajeros, para el 2010 esa cifra será de 13.800 .000 y para el 2015 de 16.890.000. Sobre el impacto de estos datos a la hora de leer paisajes literarios véase Marrero Henríquez «Del turista textual al lector ecológico». 
que parecen padritos misioneros» (33-34); «todo el mundo tiene allí un talento que pudiéramos llamar descomunal. Un simple zapatero escribe una crónica con tal aticismo y sutileza, que más bien parece página de siglo de oro o de renacimiento florentino» (34), «los comerciantes escriben novelas; los barberos, versos; los cocheros, pasodobles y misas de réquiem. Todos se aman y son iguales entre sí como los números primos» (36).

A pesar de los rasgos señalados, es una ironía rayana en el sarcasmo la que explica el título de Banana Warehouse, pues ése, afirma el prologuista, es el «título más apropiado» para un lugar y unos habitantes que no son otra cosa que «un almacén de plátanos que caminan» (197). Y en una suerte de grosería final, concluye el prologuista sobre el paraíso: «yo os aconsejo que después de leída la novela os vayáis a vivir allá. Está junto a Fernando Poo. Hay un dragón furioso, hecho de egoísmo y de odio, que guarda la entrada. Pero no importa. Le arrojáis la novela a la cabeza y os dejará pasar. Se le engaña pronto. Yo pasé enseñándole un chelín» (39).

En La isla y los demonios (1952), llega en 1938 a Gran Canaria, en calidad de refugiada de guerra y acogida por sus parientes canarios, la parte de la familia Camino afincada en Madrid. Las elevadas expectativas paradisíacas de Honesta se hacen añicos ante la costa de acantilados «tristes y estériles» que ve mientras se acerca su barco al muelle. Honesta exclama que «creía que veníamos a un paraíso» y su cuñada Matilde, «que era licenciada en Historia [y] se suponía que sus juicios eran inapelables», le contesta, taxativa, que «nada de paraísos. Estas islas son terribles» (27). Una vez atracan en Las Palmas, los refugiados atraviesan la ciudad de punta a punta, «por la larga calle León y Castillo, que une todo a lo largo el barrio del puerto y el casco de la ciudad, [y por la que] cruzaban automóviles, típicas guaguas de pasajeros, camiones. A veces la calle bordeaba el mar, por un trozo cruzaba entre la ciudad jardín y la playita de Las Alcaravaneras, donde aquel día hermoso había algunos bañistas» (31). Ante ese trayecto, que a Marta Camino, la joven protagonista canaria de dieciséis años, «le parecía lleno de color y de vida, [...] los ojos de [su recién llegado tío] Daniel, que ella consultaba, no expresaban la menor admiración. Él veía casas pequeñas, gentes despaciosas, aplastadas por el día lánguido, pesado, soñoliento» (31).

En La isla y los demonios (1952), Marta es el único personaje capaz de apreciar no sólo la belleza paradisíaca de los fértiles valles y floridos jardines de la isla, sino también la hermosura extrema de otras manifestaciones de su naturaleza: profundos y escarpados barrancos, altísimas cimas, secas planicies, solitarias playas, el cactus, la tormenta que se desata, el seco viento de Levante con su calima sofocante. El resto de los personajes Camino, tanto los refugiados — sus parientes, Honesta, Daniel y su mujer Matilde, y Pablo, el amigo pintor que los acompaña - como los oriundos, en especial José, están tan ensimismados en sus pasiones que son incapaces de ver más allá de sí, de sus recelos, envidias, resentimientos, frustraciones. 
La casa en que todos los Camino se alojan al llegar a la isla está enclavada en Tafira, en el Monte Lentiscal, cerca de la Caldera de Bandama, en un lugar por entonces de veraneo de la alta burguesía, entre árboles y viñedos, de visita turística obligada y cuya belleza ninguno es capaz de apreciar. El narrador omnisciente deja claro que la carretera de Tafira estaba «graciosamente adornada de geranios, de tapias blancas, de cercos espinosos con rosales silvestres, floridos, vallado de fincas de viñas, [que en Tafira] el invierno verdecía las cunetas [y que allí caían] tres chaparrones, y entre los negros y fríos troncos de las vides saltaba una alfombra de amapolas amarillas» (91). Sin embargo, a Matilde, «el risueño paisaje que la rodeaba se le hacía [...] silencioso y oscuro como una cárcel», y si Hones y Daniel «se encontraban a sus anchas en aquella casa [era porque], según decía Daniel, daba olor a dinero» (56). En esa hermosa finca, Pino, casada con José, se sentía ahogada, a ella le gustaba la ciudad, y «nada más salir de Las Palmas y enfilar por la carretera del centro hacia Tafira y Monte Coello, Pino volvía a su sombría angustia. Tenía la impresión de que la oscura avenida de eucaliptos que descendía entre los campos de viñas de la carretera hasta el jardín era una garganta que la tragaba» (63).

Los Camino que llegan en La isla y los demonios son refugiados de guerra y, todos, incluidos los oriundos, son refugiados del alma, seres heridos en sus sentimientos, frustrados en sus expectativas, rencorosos por una infancia desgraciada, resentidos ante el pasado, mezquinos ante el futuro. Con la excepción de la joven Marta, que aprecia con admiración las posibilidades vitales de la belleza natural de una isla de cuyos demonios desea escapar, nadie de su entorno social es capaz de disfrutar de esa carretera cercana a la casa familiar y que «subía hacia la montaña de La Caldera, sólo porque los turistas pudiesen ver la vista impresionante del redondo cráter y el gran trozo de llanura y costa que desde allí se alcanza» (91). Esa hermosa isla que nadie ve, salvo Marta que se va, es la que hizo que todavía estén unos ingleses «que fueron para unas vacaciones [...] hace treinta años» (127). Y esa hermosa isla es la que verán y admirarán los alemanes tras la segunda Gran Guerra, pues la profecía de José resulta certera, «dice que Hitler lleva a los alemanes por el camino de hacerse los dueños del mundo, y que pronto tendremos más turistas alemanes que ingleses'»(139).

Los personajes de Lorenzo Silva en La niebla y la doncella (2002) viajan a la isla de La Palma a investigar el escenario de un crimen que tuvo lugar en el parque nacional de Taburiente y que el personaje Anglada no duda en considerar «un marco incomparable» (371). Ya en la cumbre de la isla, donde se enclava el Astrofísico del Roque de los Muchachos, uno de ellos exclama: «iqué pasada, los que puedan vivir y trabajar aquí!» (373) ${ }^{11}$. Las referidas expresiones son tan tópicas como la visión del paisaje que implican, y

\footnotetext{
${ }^{11}$ Citado por Marrero Henríquez El paisaje literario. Antología.
} 
que es propia de quien hace el itinerario homogéneo del turista por la hiperrealidad programada por las agencias turísticas. El paraíso es, en La niebla y la doncella, un decorado que como tal se acepta y que sólo es objeto de atención pormenorizada en cuanto escenario del crimen.

Clichés similares a los de estos visitantes pronuncia en Los puercos de Circe (1973), de Luis Alemany, el Notable Poeta que, en la excursión que le brindan por los paisajes del Teide, es capaz de comentar con admiración llena de lugares comunes sobre un lugar que no puede ver porque está nublado: «muy bonito este paisaje — repite el Notable Poeta paseando la mirada distraída sobre el precipicio absolutamente cubierto de nubes-, muy bonito, tiene una tristeza, y una gracia al mismo tiempo...» (124). Poseído por una hiperrealidad asumida doblemente, pues «Vicente —el Notable Poeta llama Vicente a don Vicente Aleixandre- [le] habló tan bien, tan bien, de esta isla [...] de lo bonito que era todo», las apreciaciones del Notable Poeta sobre el entorno son de autómata, de quien ve lo que ha visto en los folletos de una agencia de viajes y lo que ha leído en una guía turística, aunque esté nublado. En el colmo de la impersonalidad de su percepción, el Notable Poeta apostilla: «Qué bonito es todo esto - $-[. .$.$] con la vista perdida en el horizonte ilocalizable entre las nubes-$ Me recuerda mucho a Jaén, ¿sabéis? Y a Oviedo también me lo recuerda un poco... ¿Habéis estado vosotros en Oviedo?» (126). En Los puercos de Circe la lectura del paisaje de Canarias como paraíso viene ligada a la lectura llena de tópicos de quienes lo habitan, y ambas son puestas en solfa por el contraste de lo aquél que, como turista, percibe, y de lo que percibe el oriundo del lugar y que, en letra cursiva en el original, resalta lo disparatado de una visión condicionada por el pastiche de postal, por la entradilla de la guía turística y por los lugares comunes sobre la condición humana del insular:

Queridos amigos: Sé que es costumbre en ocasiones como ésta, cuando se está terminando de comer y de beber, (Alberto piensa, con los dedos acariciando el vaso de vino todavía mediado, que ya lo único que faltaba era el discurso.) [...] pronunciar unas palabras justificando la reunión. [...] Vosotros desde la isla, en vuestro aislamiento, en vuestro encierro, en vuestra actividad provinciana, (de Mesa al Notable, del Notable a Mesa, contrastando, bueno es Mesa para...) nosotros, en Madrid, realizando la misma labor, más pública si queréis, (jestate quieto, Miguel Hernández...! Pero este tipo...,) pero más ingrata, os lo aseguro, (y Alberto ya sonríe más ampliamente,) porque después de haber pisado estas tierras — que con razón las llaman Afortunadas- [...] sabemos que en el Café Gijón no podemos tener vuestro cielo, (o de ver el cabreo progresivo de Carlos,) ni vuestra luz, ni vuestra tranquilidad isleña, que es la que os hace prodigiosos, la que hace prodigioso vuestro arte, (¿qué se creerá este tipo que es Tenerife?, masculla Alberto con los ojos clavados en) vuestras obras, vuestros cuadros, ( $\mathrm{Ma}$ nolito Trujillo que, enfrente de él,) vuestros versos, esos versos tan bonitos, ( $p a-$ rece seguir las palabras del orador,) ese arte tan maravilloso que sólo la isla puede producir: (no, coño, si ahora va a resultar que yo pinto bodegones) porque no los producís vosotros, (en vez de abstracto, aunque mejor sería no haber pintado nada en la vida, para lo que me ha servido,) lo produce la isla; y esa belleza, 
esa tranquilidad, (ni haberme acostado ayer a las seis y media) [...] es la que debe consolaros de estar encerrados, (aguantamos impasibles que este tipo nos insulte pensando que nos elogia,) porque estáis mucho más cerca, si no del Café Gijón, que maldito para lo que importa, de la verdadera belleza (porque ahora resulta [...] que mis cuadros no los pinté yo, sino el Drago,) [...] (y los poemas de Manolito no los escribió él, sino Las Cañadas, así salieron...; [...]). (89-92).

En Lanzarote (2000), de Michel Houllebecq, el narrador arriba al paraíso porque se interesa por una oferta de vacaciones de invierno. Por pura casualidad el narrador entra en una agencia de viajes, pregunta por posibles estancias de una semana a costo reducido $\mathrm{y}$, tras varias opciones acaba aceptando un paquete de una semana con todo incluido en el hotel Bougainville Playa, «de cuatro estrellas superior, según clasificación del país. Habitaciones con baño completo, secador, aire acondicionado, teléfono, televisión, minibar, [...] piscina de $1000 \mathrm{~m}^{2}$ con jacuzzi, sauna [...]. Espectáculos de bailes típicos, excursiones [...]» (13). El hotel está en Lanzarote, le había comentado ya la chica de la agencia, donde «el clima es suave todo el año [...y] clientes [...] se habían bañado en enero» (13), pero el narrador se ha interesado más por la oferta del hotel -3.290 francos por semana- que por el lugar donde está y al final vuelve a preguntar «¿dónde es eso?», «Lanzarote», le contestan. Al llegar a su destino, el narrador turista constata que Lanzarote no puede rivalizar con otros lugares en el segmento «de las vacaciones con crazy techno afternoons, [que] todavía puede hacerlo menos, por razones evidentes, en el campo del turismo verde» y que el turismo cultural desapareció con los «edificios que fueron destruidos entre 1730 y 1732 por una sucesión de terremotos y erupciones volcánicas de inusitada violencia» (19), pero poco a poco el narrador se deja impresionar por el paisaje desolado de la isla: «A nuestros pies había un completo desierto mineral. Y enfrente de nosotros una falla enorme, de varias decenas de metros de anchura, serpenteaba hasta el horizonte, cortando la superficie gris de la corteza terrestre. No se oía ningún ruido. 'Así será el mundo una vez muerto'» (50). Ese lugar mineral, sin plantas ni animales, una suerte de paraíso yermo, será edénico para el narrador turista que podrá disfrutar en playas apartadas del sexo que le ofrece la pareja de turistas alemanas lesbianas que, con él, en ese lugar, hace una excepción.

Con claridad meridiana, al llegar en el verano de 1970 a Gran Canaria, Ernst Jünger pone sobre la palestra cómo en el paraíso «se estaba edificando febrilmente en todos los sitios donde podía verse un poco de playa con arena» (572). Jünger anota en su diario sobre el estropicio que en las Islas Canarias producen los hoteles que, «como setas brotan en sus playas [...] y no de uno en uno, sino en serie. Se parecen hasta en los agujeros de las cerraduras; [y] en algún lugar de Nueva York o de Tokio estará el diseño original de todos [ellos]». Su reflexión sobre el «número siempre creciente de turistas; y en correspondencia con eso [el aumento del] personal de servicio» lo lleva a plantear una situación insostenible: «¿Qué ocurre en el caso de que 
aparezcan restricciones, una crisis económica, una guerra? No cabe invertir el proceso. Un hotel vacío se transforma pronto en un edificio en ruinas; un camarero no se reconvertirá jamás en un pastor. Lo que viene después son paisajes fantasmales» (570).

En Terapia (2000), uno de los personajes de David Lodge describe una playa similar a las que Jünger había visto urbanizar, Playa de las Américas, en Tenerife, y comenta, sin el menor atisbo de paradisíaca alabanza tópica, que allí

hay un enorme volcán $[\ldots \mathrm{y}$ ] es una desgracia que esté apagado, porque si no podría entrar en erupción y borrar Playa de las Américas de la faz de la tierra. [...] Según parece, todo esto no era más que una larga extensión de costa rocosa y estéril hasta hace unos pocos años, cuando un grupo de promotores decidió desarrollarla turísticamente, y ahora es una nueva Blackpool a orillas del Atlántico. Tiene una chabacana calle mayor que se llama avenida Litoral, en la que los embotellamientos de tráfico son constantes, a ambos lados de la cual se suceden los bares, los restaurantes y las discotecas más vulgares que te puedas imaginar, de los que salen a todas horas del día músicas ensordecedoras y olores de fritangas en medio del resplandor de luces de colorines. Aparte de todo esto, no hay nada más, sólo bloques altísimos y más bloques altísimos de hoteles y apartamentos. Es una pesadilla de cemento, sin apenas árboles o hierba. (198-199).

Eugénio de Andrade, poeta que declara su «desprecio por el lujo, que en sus múltiples formas es siempre una degradación», y que explica la pureza «de la que tanto se ha hablado a propósito de [su] poesía en términos de pasión, simplemente pasión por las cosas de la tierra, en su forma más ardiente y todavía no consumada» («La poesía» 2) en Gran Canaria, rubrica, a veinte años de la visita de Jünger, el poema «Maspalomas, sin nostalgia»: «De lejos, vine de lejos sólo para ver / estas dunas con sabor a desierto. / Debía haber venido / antes de haber chucrut / y salchichas y Wagner y Bismarck / y estos doscientos mil alemanes / que beben comen cagan en estas arenas / con obstinado afán: / putas y chulos son ahora / la limpidez / perfecta y el frescor de la mañana».

En esta línea de abierta crítica abunda un significativo fragmento de $« \mathrm{El}$ mar de todos los mares», de J. M. Marrero Henríquez:

Johnny es hincha del Manchester United y está borracho como una cuba. Su equipo ha ganado y nada mejor que celebrarlo con unas copas en el paraíso que ha comprado a módico precio en una agencia de viajes. Se ha sentado en una de las terrazas de la avenida de Las Canteras que su guía turístico le había recomendado y allí canta en un inglés ininteligible mientras levanta su cerveza brindando hacia el sol rojizo que él ve blanquinegro como una pelota de fútbol. Sobre la arena replantea las últimas jugadas del gol definitivo. Regateo doble, penetración por la esquina, centro, cabezaso a la escuadra, gol. En los chillidos de las gaviotas que revolotean sobre el arrecife revive los gritos brutales del graderío. Nada hay mejor que celebrar la victoria de su idolatrado equipo con unos buenos litros de cerveza, descamisado y con pantalones cortos en pleno diciembre, ¡qué lujo!, frente a un crepúsculo de postal. Johnny está dispuesto a aprovechar el paraíso hasta el final. No lleva la cuenta de las botellas que ha vaciado en su prominente estómago y le da igual si su conducta importuna a María, a los turistas alemanes 
que ya están cenando, a los abuelos que salen a esta hora a pasear. Le da igual, todo le da igual, menos el Manchester, menos la arena que le resulta verde campo de fútbol, menos el balón exagonal que todo lo alumbra desde el cielo, y nada le importa si tiene que bajar a vomitar a la orilla del Atlántico, pues lo ha comprado, por módico precio, en una agencia de viajes de su ciudad natal. (20).

En la tradición milenaria que relaciona las Islas Canarias con el Paraíso las referencias literarias de jaez crítico, irónico, desencantado o pesimista no son mayoría. Por el carácter premonitorio de lo que la industria turística acabaría por acarrear, cabe traer a colación que ya en 1892, en la época del turismo de salud y reposo, dos décadas antes de que González Díaz planificara industrialmente la explotación turística de Canarias y siete décadas antes de que se llevara a cabo masivamente el turismo de sol y playa, A. S. Brown observaba un territorio sometido por la demanda foránea, pues por entonces las Islas Canarias eran «un puerto en el que los barcos ingleses se prove[ían] de carbón, un jardín donde se cultiva[ban] las verduras de las mesas inglesas y un espacio recreativo o sanatorio construido y mantenido por ingleses» (26). Y de forma remota cabe también recordar a Petrarca que, en De vita solitaria (II 6,3), había roto con la tradición mítica secular y, como afirma Marcos Martínez, había insinuado «que se dicen y escriben muchas cosas de [las Islas] que posiblemente no convengan a su fama de Afortunadas, ya que sus gentes gozan de mayor soledad que el resto de los mortales, con la sola compañía de fieras y ganados» (125).

La creciente relevancia que a partir del desarrollo turístico adquieren las visiones literarias críticas del paraíso pone de manifiesto que la transformación del paisaje canario no ha sido inocua para la evolución literaria del paraíso, y que la evolución literaria del paraíso no ha sido banal para la interpretación del paisaje canario. En un rico y complejo trasiego de influencias, el paraíso literario se enriquece de otros paraísos literarios y, al mismo tiempo, de aquellos lugares que le han servido históricamente de referente. Ante este hecho, y en una suerte de paradójica contradicción, se puede suscribir, para la teoría y la crítica, la afirmación de Marrero Henríquez de que «la literatura cuanto más dice de sí, más dice del mundo, y cuanto más del mundo, más de sí» («La interpretación literaria»163).

Laurence Coupe sostiene que desde mediados de los años 70 del siglo XX gran parte de la teoría y la crítica literarias han asumido de manera general que «lo que llamamos 'naturaleza' existe en primer lugar como un término dentro de un sistema cultural afuera del cual no tiene ser ni significado, es decir, que es un signo dentro de un sistema significativo, y la cuestión de la referencia debe siempre colocarse entre enfáticos paréntesis. [...] El gran temor ha sido el de verse sorprendido cometiendo la que podría ser denominada 'falacia referencial'» $(2)^{12}$. Por reacción a la «falacia referencial» se llegó

\footnotetext{
${ }^{12}$ Mi traducción.
} 
a la «falacia semiótica». Si la «falacia referencial» había aceptado con inocencia, o con arrogancia, la posibilidad de adentrarse en la verdad de las cosas, ahora la «falacia semiótica» niega a las cosas y a los seres corporeidad y los reduce a ser significados culturales sin valores ni derechos propios.

En la era de la crisis ecológica, y a la vista de la estrecha relación entre la modificación de un territorio y la evolución literaria de su descripción paradisíaca, la teoría y crítica atentas a la representación literaria del paisaje han encontrado un lugar fructífero desde el cual analizar e interpretar textos, un lugar «a medio camino», una suerte de mediocridad áurea que equidista de «la falacia referencial» tanto como de la «falacia semiótica», y que es consecuencia de habitar con plenitud el presente. Esa equidistancia en que la teoría y la crítica literarias se han ubicado para contemplar la llegada de los turistas al edén y la evolución literaria del paraíso no es otra cosa que, en estos tiempos del signo, un signo de los tiempos.

\section{BIBLIOGRAFÍA CITADA}

Alemany, Luis (1989). Los puercos de Circe. Islas Canarias: Gobierno de Canarias,

Andrade, Eugénio de (1993). «Maspalomas sin nostalgia». Próximo al decir. José Luis Puerto (trad.). Salamanca: Amarú Ediciones, p. 99.

Andrade, Eugénio de (Noviembre 2001). «La poesía luminosa de Portugal». entrevista Javier García. Babelia 3, pp. 2-3.

Baudrillard, Jean (1988). Selected Writings. Stanford: Stanford University Press.

Brown, A. S. (1890). Madeira and the Canary Islands. A Practical and Complete Guide for the Use of Invalids and Tourists. London.

Cairasco de Figueroa, B. (1989). Antología poética. Ángel Sánchez (ed.). Islas Canarias: Gobierno de Canarias.

Coupe, Laurence, ed. (2000). The Green Studies Reader. From Romanticism to Ecocriticism. London and New York: Routledge.

Derrida, Jacques (1984). De la Gramatología. México: Siglo XXI.

G. H. M. (2001). «Un millón de camas en la nevera». Canarias 7, 25 septiembre, p. 15.

Galindo, Abreu (1977). Historia de la conquista de las siete islas de Canaria. Alejandro Cioranescu (ed.). Santa Cruz de Tenerife: Ediciones Goya.

González Díaz, Francisco (2007). Cultura y turismo. José Manuel Marrero Henríquez (ed.). Las Palmas de Gran Canaria: Cabildo de Gran Canaria.

González Díaz, Francisco (2005). Árboles. Una campaña periodística. José Manuel Marrero Henríquez (ed.). Las Palmas de Gran Canaria: Cabildo de Gran Canaria.

Houllebecq, Michel (2000). Lanzarote. Barcelona: Anagrama.

Humboldt, Alejandro de (1995). Viaje a las Islas Canarias. Manuel Hernández González (ed.). La Laguna: Francisco Lemus.

I.C.E. Instituto Canario de Estadística.

Jünger, Ernst (1995). Pasados los setenta I. (1965-1970), Radiaciones. Barcelona: Tusquets. Laforet, Carmen (2005). Santa Cruz de Tenerife: Ediciones Idea.

Lodge, David (1996). Terapia. Barcelona: Anagrama, 1996.

Marrero Henríquez, José Manuel (1999). «La interpretación literaria ante el nuevo milenio». Philologica Canariensia, n. $^{\text {ss }} 4-5$, pp. 147-166.

Marrero Henríquez, José Manuel (2001-2003). «De ecocrítica e hispanismo y de Francisco González Díaz, apóstol del arbolado modernista». Tropelías, n. ${ }^{\text {os }}$ 12-14, pp. 293-312. 
Marrero Henríquez, José Manuel (2004). «Del turista textual al lector ecoloógico», en Mariano Santa Ana (ed.), Paisajes del placer, paisajes de la crisis, pp.15-38.

Marrero Henríquez, José Manuel (2005). «Francisco González Díaz: regeneración cultural, repoblación forestal y ecología», en Francisco González Díaz, Árboles. Una campaña periodística, pp. vii-xx.

Marrero Henríquez, José Manuel (2005). «Poetics of Beauty in a Virtual Millenium», en Daniel Meyer-Dinkgräfe (ed.), The Future of Beauty in Theater, Literature, and the Arts, pp. 12-17.

Marrero Henríquez, José Manuel, coord. (2006). Pasajes y paisajes: espacios de vida, espacios de cultura. Las Palmas de Gran Canaria: Servicio de Publicaciones de la Universidad de Las Palmas de Gran Canaria.

Marrero Henríquez, José Manuel. «Cultura y turismo o el imperativo geográfico del paisaje insular», en Francisco González Díaz, Cultura y turismo, pp. vii-1.

Marrero Henríquez, José Manuel (2008). «El mar de todos los mares», 7.1.-8.1. Distorsiones, documentos, naderías y relatos, Alicia Murría, Gopi Sadarangani y Néstor Torrens (eds.). Las Palmas de Gran Canaria: Centro Atlántico de Arte Moderno.

Marrero Henríquez, José Manuel (2008). El paisaje literario. Antología. Las Palmas de Gran Canaria: Servicio de Publicaciones de la Universidad de Las Palmas de Gran CanariaGobierno de Canarias.

Marrero Henríquez, José Manuel, coord. (2009). Lecturas del paisaje. Las Palmas de Gran Canaria: Servicio de Publicaciones de la Universidad de Las Palmas de Gran Canaria.

Marrero Henríquez, José Manuel. «La crítica como refugio: animales, plantas y enclaves literarios en peligro de extinción», en José Manuel Marrero Henríquez (coord.). Lecturas del paisaje, pp. 17-32.

Martínez, Marcos (1996). Las Islas Canarias de la Antigüedad al Renacimiento. Tenerife: Cabildo de Tenerife, Centro de la Cultura Popular Canaria.

Meyer-Dinkgräfe, Daniel, ed. (2005). The Future of Beauty in Theater, Literature, and the Arts.Cambridge: Cambridge Scholars Press.

Millares, Michel Jorge (1996). «El turismo en Las Palmas a través de la revista Isla (19461969)». Boletín Millares Carlo, n. ${ }^{\circ}$ 5, pp. 367-381.

Petrarca. De vita solitaria (1943). A. Altamira: Nápoles

Quesada, Alonso (1986). Obra completa, vol. 5. Lázaro Santana (ed.). Canarias: Gobierno de Canarias - Cabildo de Gran Canaria.

Roca, Luis. «Paisajes de cine, en José Manuel Marrero Henríquez (coord.). Lecturas del paisaje, pp. 157-174.

San Isidoro de Sevilla. Etimologías, 2 vols., José Oroz Reta, José (trad.), Madrid: BAC, 1982.

Santa Ana, Mariano de, ed. (2004). Paisajes del placer, paisajes de la crisis. Taro de Tahíche: Fundación César Manrique.

Stone, Olivia M (1995). Tenerife y sus seis satélites, 2 vols, Juan S. Amador Bedford (trad.). Las Palmas de Gran Canaria: Ediciones del Cabildo Insular de Gran Canaria, 1995.

Torriani, Leonardo (1999). Descripción de las Islas Canarias, Alejandro Cioranescu, (ed.). Santa Cruz de Tenerife: Cabildo de Tenerife.

Viera y Clavijo, Joseph de (1982). Historia de Canarias, 2 vols, Alejandro Cioranescu (ed.). Santa Cruz de Tenerife: Goya.

Fecha de recepción: 11 de diciembre de 2009

Fecha de aceptación: 16 de julio de 2010 